\title{
El modelo de Rubén Darío en la crítica de la Edad de Plata. Los ecos en la prosa de Francisco Valdés
}

\author{
Guadalupe Nieto Caballero ${ }^{1}$
}

Resumen. Este artículo ofrece una nueva lectura de la prosa de Rubén Darío a partir de su proyección en escritores posteriores. De manera más precisa, el análisis gira en torno a la labor como crítico de Rubén y a la asimilación de su modelo por Francisco Valdés. Para ello se parte de la recepción de la obra del nicaragüense en la Edad de Plata y de unas notas sobre su proceder crítico, para después plantear el estudio de la crítica literaria llevada a cabo por Valdés y el cotejo de sus textos. El artículo, en suma, demuestra la vigencia del modelo de Darío en la prosa crítica de la Edad de Plata a partir del ejemplo de Francisco Valdés.

Palabras clave: Rubén Darío; Francisco Valdés; Edad de Plata; crítica literaria, Letras.

\section{[en] Rubén Darío’s Model in the Spanish Silver Age Literary Criticism. Echoes in Francisco Valdés's Prose}

\begin{abstract}
This article offers a new reading of Rubén Darío’s prose from his influence in following writers. More specifically, the analysis deals with Rubén's critical work and Francisco Valdés's conscious use of his model. To do so we have used both the reception of the Nicaraguan's work by Silver Age best-known authors and notes on his well-established model for literary criticism. This is followed by a detailed analysis of Valdés's literary criticism and a comparison of his works and Rubén Darío’s. In sum, using Francisco Valdés as a case study, this article demonstrates the influence of Darío's model on the Spanish Silver Age criticism.
\end{abstract}

Keywords: Rubén Darío; Francisco Valdés; Spanish Silver Age; Literary Criticism; Literature.

Sumario. 1. Introducción. 2. La recepción de Darío en la Edad de Plata. 3. Apuntes sobre el modelo crítico de Rubén Darío. 4. Francisco Valdés, lector y crítico literario.5. La labor crítica de Francisco Valdés con Rubén Darío al fondo. 6. De Letras a Letras. Notas sobre la concepción de la obra valdesiana. 6.1. Estructura. 6.2. Estilo.

Cómo citar: Nieto Caballero, G. (2018) El modelo de Rubén Darío en la crítica de la Edad de Plata. Los ecos en la prosa de Francisco Valdés, en Anales de Literatura Hispanoamericana 47, 171-187.

\section{Introducción}

1 Universidad de Extremadura, Cáceres. España.

E-mail: gnieto@unex.es 
Hay muchas prosas en la obra de Rubén Darío: cuentos, prosa poética, crónicas de viaje, crítica literaria, autobiografías y comentarios políticos. De entre esa producción, los artículos de crítica literaria, publicados en medios periodísticos como La Nación y posteriormente algunos recogidos en forma de libro, suscitaron numerosas reacciones. Su puesta de largo en el contexto literario hispanoamericano y español de la época despertó halagos y recelos por igual, pero abrió el camino a una nueva prosa crítica, muy personal y en la que Darío demostraba ser conocedor de la obra completa del autor reseñado. Esa prosa ya la practicaban críticos franceses como Anatole France (1844-1924) y Jules Lemaître (1853-1914), y tuvo continuidad en escritores españoles coetáneos o inmediatamente posteriores como Azorín (1873-1967) o Francisco Valdés (1892-1936). Este último, en el que se centra este artículo, fue un escritor periférico que sin embargo participó de los movimientos de renovación de la prosa ensayística de la Edad de Plata ${ }^{2}$. De forma más concreta, desarrolló una prosa crítica basada, en parte, en el modelo literario de Darío. Además de los comentarios hacia la obra del nicaragüense en sus artículos, los ecos de la crítica dariana son innegables en su trayectoria.

Para el análisis de la labor crítica desempeñada por Francisco Valdés siguiendo el magisterio de Darío se hace necesario enmarcar la producción de ambos en su contexto y observar la recepción de la producción del nicaragüense en los años posteriores a su muerte. Proponemos asimismo un acercamiento al modelo de Darío, a sus formas y a su propia visión de la crítica, para delinear posteriormente el esquema de la crítica de Valdés. Un hecho — fundamental- que refuerza esa dependencia referencial de Valdés con respecto a Darío sería el título de uno de sus libros, Letras (Notas de un lector) ${ }^{3}$ (1933), que sigue la estela de las Letras de Darío, publicadas en $1911^{4}$. El último apartado del artículo lo dedicamos al análisis crítico y a la puesta en común de ambos volúmenes.

\section{La recepción de Darío en la Edad de Plata}

A continuación se rescatan algunos comentarios, actitudes y anécdotas en torno a la trayectoria de Darío en las promociones inmediatamente posteriores que tratarán de justificar, en parte, el magisterio ejercido por el nicaragüense. Darío no dejó indiferente a las principales figuras literarias del primer tercio del siglo XX en

2 El término Edad de Plata hace referencia al periodo literario que transcurre entre el Noventaiocho y las vanguardias y el Veintisiete y que incluye, además, a la generación intermedia del 14 o novecentista. Aunque hay mayor coincidencia en su término (1936, con el estallido de la Guerra Civil), no está tan claro su comienzo: hay autores (Julio Caro Baroja 1972, Hernán Urrutia 2000) que lo sitúan en 1868, y otros (JoséCarlos Mainer 1981) en 1902. En cualquier caso, se refiere a la intensa actividad literaria que nace fundamentalmente con el nuevo siglo y que ha sido considerada como uno de los momentos más brillantes de toda la cultura española — de ahí su casi equiparación con el Siglo de Oro-.

3 Francisco Valdés (1933), Letras. Notas de un lector, Madrid, Espasa-Calpe, 190 páginas. Pueden consultarse ejemplares de la primera edición en la Biblioteca Nacional de España (BNE), en la Biblioteca de Extremadura y en la Biblioteca Pública del Estado “Antonio Rodríguez Moñino-María Brey” de Cáceres. Asimismo, una vez expirados los derechos de autor en enero de 2017, se puede acceder al ejemplar digitalizado en la Biblioteca Digital Hispánica (BDH) de la BNE (http://bdh-rd.bne.es/viewer.vm?id=0000201578\&page=1) (Fecha de acceso: 26/06/2017).

4 Rubén Darío (1911), Letras, París, Garnier Hermanos, 237 páginas. Es difícil localizar primeras ediciones de la obra. No obstante, la BNE cuenta con un ejemplar y puede consultarse, además, la versión en línea de la BDH (http://bdh-rd.bne.es/viewer.vm?id=0000201174\&page=1) (Fecha de acceso: 26/06/2017). 
España e Hispanoamérica; fue, para muchos, "el comienzo absoluto de una modernidad aparentemente contradictoria” (Rovira 2009: 129). Entre las voces laudatorias está la de Gerardo Diego, que en 1927 reconoció el mérito de Darío en su labor por recuperar la figura de Góngora, tan ausente en la poesía del siglo anterior:

Porque al doblar el cabo del novecientos ya sabéis que Rubén Darío el bueno volvió a nosotros con la poesía recién viva entre sus trémulas manos, y con ella la devoción a nuestro don Luis, ya presentidamente saludado por los simbolistas franceses. [...] Las nuevas flores que han brotado después para gloria de nuestra poesía y honor de don Luis de Góngora, no me atreveré yo a robarlas a los vigilantes cuidados hortelanos (en Rozas 1987: 331).

En una línea similar, Pedro Salinas también admiraba al poeta y reconoció haberse iniciado en la poesía en pleno modernismo, movido, entre otras lecturas, por la obra del nicaragüense (Salinas 1975: 41). Llegó a visitarlo en París justo antes de su muerte y en 1948 publicó La poesía de Rubén Darío, libro en el que ofrece un acercamiento a su vida y obra y en el que confirma a Darío como iniciador de la poesía hispánica contemporánea. Dámaso Alonso, por su parte, comparaba el descubrimiento de Darío en su adolescencia con el que un joven de mediados del siglo XVI hubo de experimentar con San Juan de la Cruz: “¡Qué novedad de voz, qué extrañeza de colorido, qué inaudita musicalidad, qué incógnito mundo de arte!” (Alonso 1942: 97). Alonso plantea así un puente entre ambos momentos de la historia literaria española. Otro enlace es el que establece Jorge Guillén con la poesía hispanoamericana a partir de la figura de Darío, insistiendo en que hay una continuidad entre el grupo poético del Veintisiete y toda la poesía anterior (Guillén 1999: 534).

Entre los recuerdos hacia el vate nicaragüense y su poesía destaca, sin duda, por peculiar y reivindicativo, el discurso "al alimón” pronunciado por Federico García Lorca y Pablo Neruda en 1933 en Buenos Aires. El tema y propósito del discurso no era otro que enaltecer a Rubén Darío, fallecido diecisiete años antes y, a juicio de los dos poetas, "muy injustamente olvidado en la metrópoli argentina", a la que le dedicó su Canto a la Argentina (1914) (Gibson 2014: 55). En palabras de Neruda, “Aquel discurso fue dedicado a Rubén Darío, porque tanto García Lorca como yo, sin que se nos pudiera sospechar de modernistas, celebrábamos a Rubén Darío como uno de los grandes creadores del lenguaje poético en el idioma español” (Neruda, 1974: 154). En una de las intervenciones de Lorca en el discurso, el granadino afirmaba que "Como poeta español enseñó en España a los viejos maestros y a los niños, con un sentido de universalidad y de generosidad que hace falta en los poetas actuales. Enseñó a Valle Inclán y a Juan Ramón Jiménez, y a los hermanos Machado" (Neruda 1974: 156).

Por otra parte, entre los objetores y críticos de la joven literatura con la obra de Darío destaca Luis Cernuda. El sevillano fue siempre duro con el Modernismo y con el autor de Azul... Sostuvo que el movimiento modernista se había limitado a los poetas simbolistas menores y ensalzaba la figura de Juan Ramón Jiménez como ejemplo del poeta capaz de discernir y reconocer "lo definitivo dentro de la poesía 
universal” (Cernuda 1994a: 56). En 1942 cargó de nuevo las tintas contra el Modernismo, acusándolo de haberse detenido en "lo externo y lo ornamental" (Cernuda 1994b: 161). El volumen de Rubén Darío en Oxford (1966) es otra prueba más de ello. El libro, promovido por la Academia Nicaragüense de la Lengua, contó con las opiniones favorables de Arturo Torres Rioseco y Ernesto Mejía Sánchez, y con la actitud crítica de Maurice Bowra y Cernuda.

En cualquier caso, la figura de Darío siguió presente en las promociones posteriores, situándose, en muchas ocasiones, en medio de debates y comentarios. Todos estos escritores se habían sentido marcados por el escritor americano. Un ejemplo diferente - pero no único- es Francisco Valdés. El escritor extremeño, que formó parte de la órbita de las vanguardias regionalistas, leyó y entendió su obra, especialmente la de crítica literaria, y en 1925 manifestó, en la línea que adoptarían posteriormente Lorca y Neruda, que "le seguimos siendo tributarios de muchos homenajes". Consideraba que de haber pertenecido a un medio más literario que el hispanoamericano, "es indudable que la bibliografía sobre su obra de excelsitud alcanzara proporciones de palacio y no de choza”. Para Valdés (1925), la obra de Darío había ejercido y ejercía en 1925 un importante influjo en las letras españolas y americanas:

Rubén Darío fue la estrella de Oriente en la literatura española del novecientos, con sus claros rayos guiadores y con los otros, deslumbrantes y cegadores. Pese a las novísimas corrientes de poesía, aún se alzan sus versos vívidos y llenos de clamores. Sus versos polifónicos, huguescos, simbolistas y parnasianos.

Pero el extremeño fue más allá y reconoció el mérito de la prosa de Darío, a quien tomó como modelo y a quien hizo un guiño con sus Letras (Notas de un lector) en 1933. A la luz de estos comentarios y posturas es innegable considerar que la vanguardia hispánica mantuvo una deuda con la trayectoria del vate nicaragüense.

\section{Apuntes sobre el modelo crítico de Rubén Darío}

En el artículo "La crítica”, publicado en 1899 en La Nación, de Buenos Aires, e incluido posteriormente en las crónicas de España contemporánea (1901), Rubén Darío reflexiona sobre la pobreza generalizada de la crítica española, dirigida a un público poco letrado y temeroso de innovaciones. Se lamenta de que la crítica "tiene que encogerse, tiene que rebajarse para ser aceptada" (Darío 1907: 296), y cita como ejemplos los Paliques de Clarín, un tipo de crítica literaria asequible para los lectores del momento, o los comentarios de Balart, que carecen, a su juicio, de sentido estético. Ante este panorama, reivindica una crítica literaria nueva, audaz, capaz de valorar y defender la literatura innovadora de la época. Esta nueva crítica "no se deja arrastrar por las modas literarias, ni se somete a las presiones del entorno cultural, ni al gusto del público. Trasciende los límites de la mera exposición, del simple análisis, de la precisa pero limitada explicación” (Utrera Torremocha 1998: 80). 
En su prosa, Darío no pretende esbozar la obra de un escritor, "ni quiere tampoco enseñar nada, ni someter la belleza artística a un análisis empobrecedor”; Darío responde a un concepto fundamental de la crítica literaria: la determinación del valor literario (Utrera Torremocha 1998: 81). Su actividad crítica se caracteriza, principalmente, por el escepticismo y la subjetividad, valores que no coinciden con la concepción actual de la crítica. En el proceder crítico adoptado por el nicaragüense es común la contaminación estilística del lenguaje de la obra que se reseña, algo que se da también en la crítica de Francisco Valdés, como se verá. Esta es otra de las razones por las que esta crítica literaria puede concebirse como un texto literario más. Como señala Barthes (1973: 37-38), no se puede hablar del texto, sino que solo se puede hablar en él a su manera y entrar en un terreno de plagio desenfrenado ${ }^{5}$.

La identificación entre crítica y literatura formaba parte del credo estético e impresionista, en auge en el siglo XIX. El origen de este método, entendido como una de las variantes del enfoque histórico y biográfico de la crítica literaria, suele atribuirse a Charles Sainte-Beuve (1804-1869) e Hippolyte Taine (1828-1893), y se centra, principalmente, "en lo que el crítico siente ante la obra de arte" (Álvarez Gardeazábal 2005: 104). Grosso modo, el método propuesto y defendido por Sainte-Beuve se interesa por los datos de la biografía del autor que puedan arrojar luz sobre la obra, por aquellos que puedan delinear la personalidad del autor y por los que, "de forma general, pueden ser utilizados para el estudio de la psicología de la creación artística”6 (Viñas Piquer 2002: 329). Entre los autores que defienden y participan de este proceder crítico destacan Charles Baudelaire (1821-1867), Oscar Wilde (1854-1900) y Arthur Symons (1865-1945), referentes de Darío, así como Ramón Pérez de Ayala (1880-1962), Juan Ramón Jiménez (1881-1958), Gregorio Martínez Sierra (1881-1947) y Azorín en el contexto español. Un aspecto indiscutible de este método es, por tanto, la combinación de las impresiones personales del crítico ante la obra comentada con anécdotas e información personal y literaria del autor en cuestión. El carácter innovador de esta crítica despertó halagos y recelos, de ahí que algunos hayan visto en el volumen de Los raros (1896) de Darío un ejemplo de alabanza o semblanza literaria más que de crítica literaria.

Asimismo, el hecho de que la mayoría de estos textos fueran publicados inicialmente en periódicos justifica la brevedad y la condensación estilística, pues es un medio que destaca, precisamente, por su inmediatez e interés por informar y comentar obras actuales. Tanto Darío como Francisco Valdés son ávidos lectores, ojo avizor siempre a las últimas novedades del momento. En el prólogo a Opiniones (1906), el nicaragüense reconoce que no pretende enseñar nada, pues su propósito no es otro que exponer "mis opiniones y mis sentires, sobre cosas vistas e

5 La cita original es la que sigue: “vous ne pouvez parler 'sur' un tel texte, vous pouvez seulement parler 'en' lui, à sa manière, entrer dans un plagiaté perdu, affirmer hystériquement le vide de jouissance” (Barthes 1973: 37-38).

6 Taine se sitúa en el camino del método biográfico practicado por Sainte-Beuve, pero pretende dar a la literatura un tratamiento científico. Así, como apunta Viñas Piquer (2002: 332), "trata de explicar los hechos literarios y el estado moral desde el que nacen como resultado de la combinación de tres factores: la raza, el medio y el momento". Le interesa la literatura más como documento que como monumento, pues esta “conserva la huella del hombre que lo creó" y considera, por tanto, que a partir de los textos puede reconstruirse la vida del escritor. 
ideas acariciadas. Todo expresado de la manera más noble que he podido [...] No busco el que nadie piense como yo, ni se manifieste como yo" (Darío 1917: 6). En este libro incluye crónicas sociales y literarias (sobre la prensa francesa, por ejemplo) y otras reflexiones sobre poetas españoles y franceses. Véanse los epígrafes sobre Zola, Jean Moreas o José María Heredia - a los dos últimos se referirá también en Letras (1911)—, o el dedicado a los poetas españoles del momento, entre los que incluye a los hermanos Machado, Pérez de Ayala, Antonio de Zayas, Juan Ramón, Villaespesa y Andrés González Blanco. Insiste en que en sus líneas puede olvidar, seguramente, "a otros buenos poetas, gentiles adoradores de las musas. Mas hay que ver que aquí indico únicamente mis preferencias” (Darío 1917: 209).

En Los raros, Darío, siguiendo el método impresionista, incluye anécdotas e información biográfica que configuran verdaderos cuadros líricos. De esta literatura nace el libro Españoles de tres mundos (1942) de Juan Ramón Jiménez, una colección de caricaturas líricas de escritores que habían dado al panorama español de la primera mitad del siglo XX su idiosincrasia particular ${ }^{7}$. En Cabezas (1916) delinea un perfil del autor en cuestión, incluye detalles personales y expone una serie de sugestiones lectoras. Resulta complicado encasillar esta obra, pero el propio Darío, en carta al poeta de Moguer, habla de él como un "libro de crítica" (en Utrera Torremocha 1998: 92n) ${ }^{8}$.

Los ensayos de crítica impresionista de Darío suelen tener una estructura más o menos fija que incluye los siguientes elementos: exordio o justificación del acercamiento a la obra del autor escogido, revisión de su obra y análisis de los principales rasgos estilísticos de la obra reseñada o del conjunto de su producción, mención de las posibles influencias literarias recibidas e irradiadas a otros escritores, la inclusión de datos históricos y anécdotas personales del autor y la reproducción, en ocasiones, de fragmentos de la obra. Todo ello conforma un metadiscurso en el que convergen diferentes perspectivas que abordan su objeto de estudio. Véanse algunos de los rasgos mencionados en los siguientes fragmentos extraídos de "Zorrilla de San Martín”, cuadro incluido en Cabezas"

\begin{tabular}{|l|l|}
\hline Hace veinte años que vi por la primera vez a este admirable & Exordio \\
uruguayo. Los que le conocen me han dicho que, hoy como antes, & \\
anima un espíritu encendido y palpitante aquel cuerpo que crece & \\
al resplandor de la frase oratoria, aquella cabeza de tribuno, & \\
aquella cabeza de poeta. Y como vive de fe y respira esperanza, & \\
se diría que una inagotable juventud conserva firmes sus nervios, \\
airoso sugesto, cálida y vivificante su palabra, toda energía y & \\
ritmo. & \\
\hline $\begin{array}{l}\text { Su negra y copiosa cabellera se agitaba en la conmoción de las } \\
\text { arengas; el brazo diestro se alzaba como arrojando, como }\end{array}$ & $\begin{array}{l}\text { Anécdotas } \\
\text { información } \\
\text { esparciendo, como regando las oraciones; los ojos, la máscara }\end{array}$ \\
\hline
\end{tabular}

7 El volumen agrupa 61 retratos que habían venido publicándose en la prensa desde 1915, entre ellos, uno dedicado a Rubén Darío.

8 Carta incluida en Juan Ramón Jiménez (1990). Mi Rubén Darío (1900-1956). Moguer: Fundación Juan Ramón Jiménez, p. 113. Citamos a partir de María Victoria Utrera Torremocha (1998: 92n).

9 Citamos por la siguiente edición: Rubén Darío (1929). Cabezas: pensadores y artistas, políticos, novelas y novelistas. Madrid: Imprenta de Galo Sáez, pp. 45-48. 
toda contribuían a la conquista de los auditorios; y un común orgullo nos producía a los neomundiales la victoria de aquel hombre generoso y lírico, que había cantado al épico charrúa Tabaré, y saludaba en vibradores y musicales períodos, en nombre de las naciones nuevas, a la regia decaída y maternal España.

Con Tabaré y con la Leyenda Patria-que celebraron poetas comoOlegario Andrade, autoridades como Paul Groussac-se colocó Zorrilla de San Martín en el escaso número de los grandes líricos americanos.

Se ha dicho que siempre en el poeta aparece la amplitud, la exuberancia oratoria. No olvidemos que ello es una característica de Víctor Hugo, y más cerca y no a tañías alturas, de Núñez de Arce. Es una elocuencia llena de lirismo, y esto lo admiramos hasta en el mismo viejo Esquilo.

En Tabaré [...] encontré en días en que imperaban endémicas doctrinas, una novedad sana y un sentido de musicalidad honda y trascendente, que venían de la influencia de un poeta «menor» pero de los más dignos de admiración y amor en la España del siglo pasado: Bécquer. «Mi Gustavo Bécquer, genio admirable y querido, despertador de mi adolescencia poética», dice Zorrilla de San Martín en una confesión reciente publicada en Mundial.

Cuadro 1. Planteamiento general de la estructura de los artículos de prosa crítica de Rubén Darío.

Este esquema se repite, con mayor o menor versatilidad, en textos posteriores. En sus ensayos, Darío deja entrever un mapa de la cultura de su época, rescatando para ello las rarezas de algunos escritores, "los diferentes grados de sus eminencias” (Anderson-Imbert 1967: 70), los libros y otras críticas periodísticas que consulta, sus autoridades críticas o sus anécdotas con otros hombres de letras. Las descripciones impresionistas de Darío en estos ensayos suelen apoyarse en la alternancia de párrafos de periodo largo $-\mathrm{y}$ tono cercano al oratorio-y oraciones breves. Estas descripciones impresionistas se apoyan también en figuras como la anáfora, el asíndeton, exclamaciones y preguntas retóricas, "nuevo recurso de gran dinamismo para una prosa de análisis y exposición conceptual” (Conejero 1985: 229-230), y en el ritmo interno, propio de la literatura modernista. El siguiente fragmento, tomado del cuadro de "Leconte de Lisle", de Los raros, resume los aspectos mencionados:

¡Homéricos funerales para quien fue homérida, por el soplo épico que pasaba por el cordaje de su lira, por la soberana expresión y el vuelo soberbio, por la impasibilidad casi religiosa, por la manificencia monumental, estatuaria de su obra, en la cual, como en la del Padre de los poetsa, pasan a nuestra vista portentosos desfiles de personajes, grupos esculturales, marmóreos, bajorrelieves, figuras que encarnan los oídos, los combates, las terribles iras; homérida por ser alma y sangre latinas y por haber adorado el lustre y el renombre de la Hélade inmortal! (Darío 1920: 31) 
Como propone Conejero (1985: 230), la prosa ensayística es, a diferencia de la literaria, una forma no acabada, abierta, "y cuyo valor depende no de las ideas expuestas, sino del poder de sugerencia que ellas puedan despertar en el receptor, convertido en lector activo”. Así, “Valiéndose de esta forma el crítico modernista creará, sin embargo, un discurso poético circular 'literaturizado' a través del 'ritmo de pensamiento"”. Por medio de sus juicios y reflexiones, Darío contribuiría a “introducir a Hispanoamérica dentro de un presente universal de transformación artística que pretendía rescatar la Belleza Ideal de los orígenes de la civilización occidental” (Conejero 1985: 230).

\section{Francisco Valdés, lector y crítico literario}

Francisco Valdés Nicolau (Don Benito, Badajoz, 1892-1936) cultivó con notable acierto tanto prosa crítica como creativa, aunque en ocasiones los límites entre una y otra se desdibujan. Procedente de una familia de terratenientes, en 1910 se marcha a Madrid para cursar sus estudios universitarios, estancia que mantuvo, de manera intermitente, hasta 1929, fecha de su vuelta definitiva al pueblo. Durante estos años, el escritor extremeño se empapó de las novedades literarias que se manifestaban con mayor o menor éxito en la capital y trató de hacerse eco y acercarlas a los lectores extremeños a través de la prensa regional.

El escritor fue partícipe de la renovación cultural de la Edad de Plata en las primeras décadas del siglo XX. Colaboró asiduamente en publicaciones de la época como La Gaceta Literaria, Bética, Acción Nacional o el Correo de la Mañana de Badajoz. Su huella quedó marcada, fundamentalmente, en textos de crítica literaria que abordaban obras clásicas y coetáneas, siguiendo el modelo de Darío y Azorín, otro de los constantes referentes en su obra. La prosa impresionista de Valdés tiene también fondo en la obra de Miró y Pérez de Ayala. A Darío rendirá recuerdo y su reconocimiento en el volumen de Letras, no solo por la denominación —enlazando con la obra homónima de aquel- sino también por el contenido y el proceder crítico que plantea en su obra. El cotejo de este volumen con el de Darío se hará en el apartado quinto.

Letras vino a ser la continuación de Resonancias (1932), volumen en el que el escritor recrea obras clásicas y coetáneas de la literatura española desde el prisma de un lector culto. Entre sus páginas propone un acercamiento a Pequeñas memorias de Tarín (1915) de Sánchez Mazas o a Aurora Roja (1904) de Baroja, entre otras lecturas, ofreciendo una trama distinta pero fácilmente reconocible desde su perspectiva lectora y siguiendo el modelo de Azorín en Castilla y Lecturas españolas, ambas de1912. En el volumen de Letras, las glosas del escritor siguen la línea del lenguaje del ensayo clásico y plantea las excelencias o deficiencias de un escritor, aunque siempre desde el ejercicio de la lectura.

Otra vertiente de la producción valdesiana, a la que hemos hecho mención, es la prosa creativa. En prensa publicó numerosos artículos, muchos de ellos bajo el epígrafe de "Estampa", en los que dibujaba la vida en el campo extremeño, dando voz así a sus sufridos protagonistas. Algunos de estos artículos los publicó posteriormente en forma de libro: Cuatro estampas extremeñas con su marco (1924) y 8 estampas extremeñas con su marco (1932). El molde empleado es el 
de la estampa, que enlaza con los géneros románticos del cuadro de costumbres y el tipo, así como con los relatos de Miró en El ángel, el molino, el caracol del faro $(1921)^{10}$. En estos textos, Valdés ofrece una rica visión de un mundo de cosas íntimas y cotidianas, como el despido de una joven campanera, el olvido al que son condenados los hombres del campo o la humilde vida de un modesto carpintero que consigue, con mucho esfuerzo, sacar a su familia adelante. En estos textos, la naturaleza es captada sensorialmente; el lector puede ver, escuchar y hasta oler y palpar las manifestaciones vitales de estos seres:

Este hombre, sentado en un trípode encinero y patizambo, junto al fuego de una humosa y rústica cocina, lía, auxiliado de una navaja, unas briznas de tabaco, y dando un gaucho suspiro, ha dicho: Yo lo único que siento es morirme. [...] Hoy, este hombre se inclina a la tierra desde su nacimiento. Sus espaldas se agobian de tanta y tan cruenta inclinación. Sus ojos toman los apagados resplandores de la arcilla. (Valdés 2013: 69)

La configuración de la estampa implica un estatismo formal y, a la vez, dinamismo y fluencia lírica del contenido. Las Estampas de Valdés son el paradigma de la unión de narración, evocación y lirismo, construido en torno a un proceso de recuerdo con un argumento mínimo. La revelación de las tragedias de sus protagonistas otorga intensidad emotiva e interés ficcional.

Sin embargo, si por algo destaca la producción de Francisco Valdés es por su actividad crítica en la prensa de la época. Su labor como crítico literario logró un amplio reconocimiento en publicaciones de las primeras décadas del siglo XX. De hecho, en 1932 y 1933, en sendos artículos de José López Prudencio en el $A B C$, se le incluye entre los escritores que han protagonizado "la vida literaria" de esos años. En 1932 aparece como uno de los partícipes de una literatura que busca "en la Filosofía y en la Historia el sentido auténtico de la vida nacional” y trata de orientarla "por sus caminos propios a la reconquista de su misión particular" (López Prudencio 1933a); en 1933, por su parte, López Prudencio (1933b) alaba los ensayos de crítica literaria de Letras. La mayoría de sus colaboraciones, que se encuentran aún dispersas entre las revistas y periódicos de entonces, constituyen un importante fondo documental que debe tenerse en cuenta para reconstruir el panorama estético en que se desarrolla la prosa de los años veinte y treinta $\mathrm{y}$, de manera particular, en el ámbito de la literatura en Extremadura.

\section{La labor crítica de Francisco Valdés con Rubén Darío al fondo}

Como ya se ha mencionado más arriba, la crítica impresionista propone un acercamiento a la literatura desde posiciones subjetivas, “confiando en la impresión personal que una obra causa en el crítico-lector”, y busca explicar la belleza de la obra "de forma intuitiva” más que enjuiciarla (Viñas Piquer 2002: 345). Rubén Darío pretendía dar cuenta de las impresiones que una obra le causaba en un

10 El subtítulo del libro es precisamente Estampas rurales y de cuentos, estampas de un león y una leona, estampas del faro. 
momento concreto. Las ideas emanadas de la lectura son expresadas por el crítico como si estuviera escribiendo una obra literaria, razón que explicaría el tono poético de estos textos. La obra crítica, por tanto, es también una obra artística. Este modelo, introducido en buena medida por Darío en el contexto español e hispanoamericano, tuvo repercusión en autores coetáneos e inmediatamente posteriores como Azorín y Francisco Valdés.

En la línea del autor de Los raros, Valdés se afanó en reivindicar a escritores del momento y a otros que, a su juicio, habían sido injustamente olvidados. Lo hace en una prosa poética y libre en la que deja fluir sus impresiones como lector. Entre los autores coetáneos se encontraban Juan Ramón Jiménez ${ }^{11}$, Pío Baroja ${ }^{12}$, Antonio Machado ${ }^{13}$ o Gerardo Diego ${ }^{14}$. Por otra parte, entre los escritores que normalmente escapaban del canon y a los que Valdés dedicó su atención figuran Luis Ruiz Contreras (1863-1953) ${ }^{15}$, al que considera un olvidado del Noventaiocho, Aleksandra Kolontái (1872-1952) ${ }^{16}$, José María Salaverría (1873-1940) ${ }^{17}$ o Joaquín Montaner (1892-1957) ${ }^{18}$. Pero también actualiza a autores clásicos como Santa Teresa, Fray Luis, Séneca ${ }^{19}$ o Cervantes $^{20}$. Valdés propone un acercamiento a la literatura desde posiciones subjetivas cuya finalidad última es, sobre todo, extraer y explicar la belleza de la obra. Evidentemente, esta concepción crítica implica, en la mayor parte de los casos, seleccionar escritores hacia los que se tiene una actitud favorable.

En las reflexiones lectoras de Francisco Valdés se advierten, como en la de Darío, detalles biográficos y anécdotas personales. No obstante, en la prosa valdesiana conviene precisar diferentes matices. El extremeño plantea, por un lado, una crítica artística e impresionista, donde lo biográfico, las anécdotas personales y la evocación de los ambientes literarios filtrados por el recuerdo tienen gran peso. Las referencias a la obra y su puesta en común con la de otros autores completan esa visión impresionista. Esta sería la línea más cercana a Darío y en la que mejor se aprecia su modelo. El segundo cariz de la crítica de Valdés es aquel en el que prescinde de amplios comentarios sobre la vida del escritor que reseña y se centra, fundamentalmente, en la obra que comenta o en la trayectoria del autor. Sigue siendo una crítica impresionista y subjetiva que parte de sus impresiones de lector,

11 “Motivos sobre Juan Ramón”, en Letras (Notas de un lector) (1933), pp. 101-112.

12 “Al margen de los libros. Indicaciones sobre Baroja”, en Correo de la Mañana (17/01/1923), p. 2, y “Tres fechas sobre Baroja”, en Letras (Notas de un lector) (1933), pp. 143-155.

13 "Nuestros poetas. Antonio Machado", en Bética (05/11/1914), pp. 7-8, y "Paralelo soriano", en Letras (Notas de un lector) (1933), pp.. 189-200.

14 “Paralelo soriano”, en Letras (Notas de un lector) (1933), pp. 189-200. En este artículo, Valdés propone un acercamiento a las simetrías de ambos autores en sus cantos a las tierras sorianas en Campos de Castilla (1912) y en Soria. Galería de estampas y efusiones (1923). El libro de Diego pertenecía a la colección "Libros para amigos” de Espasa-Calpe, promovida por José María Cossío, y en la que apareció también el volumen de Cuatro estampas extremeñas con su marco de Valdés.

15 “La generación del 98. Un olvidado”, en Heraldo de Zamora (29/09/1914), p. 1.

16 "Alejandra Kolontay. La mujer nueva y la moral sexual. Versión española de M. Teresa Andrade, 1931. (Hoy)”, en La Gaceta Literaria (15/09/1931), p. 15.

17 “Un periodista español”, en Correo de la mañana (25/06/1919), p. 1.

18 “Leyendo. Primer libro de odas”, en Bética (28/04/1916), pp. 11-12.

19 “Misticismo, muy siglo XVI”, en Bética (30/10/1915), pp. 1-2.

20 "Pericia geográfica de Miguel de Cervantes", en Correo de la Mañana (27/01/1922), p. 3, y "Homenaje a Cervantes”, en Resonancias (1932), pp. 55-68. 
pero más concisa y adaptada al medio en que aparece, que suele ser el periódico, caracterizado por la brevedad e inmediatez de la información.

Como veíamos en el cuadro de Darío dedicado a "Zorrilla de San Martín", incluido en Cabezas, el autor expone una serie de detalles sobre sus impresiones lectoras, la puesta en común de la obra del escritor en cuestión con la de otros autores semejantes o traslada a la glosa una serie de resonancias literarias que enriquecen el texto. Recuperamos ahora el esquema planteado en torno a esa estructura y vemos su aplicación como modelo en la crítica de Valdés (1924b) en un artículo aparecido en el Correo de la Mañana el 6 de diciembre de 1924 y titulado "Notas de un lector. Aparición de dos poetas". El texto se divide en dos partes claramente diferenciadas, por lo que, para simplificar, exponemos ejemplos de la estructura en la segunda parte, dedicada a Pedro Salinas:

\begin{tabular}{|c|c|}
\hline $\begin{array}{l}\text { El año corriente de } 1924 \text { ha sido de gracia para la poesía } \\
\text { madrileña. Se han señalado en él dos áureos acontecimientos: } \\
\text { la publicación de las «Nuevas Canciones», de Antonio } \\
\text { Machado -lo más depurado que ha surgido de su inspiración } \\
\text { depurada-, y la aparición de dos poetas en el Parnaso } \\
\text { nacional. Uno antiguo: Pedro de Medina Medinilla; otro } \\
\text { moderno: Pedro Salinas. Prescindamos del primer suceso } \\
\text { (otro día le glosaremos) y calemos con atención el segundo. }\end{array}$ & Exordio $^{21}$ \\
\hline $\begin{array}{l}\text { El segundo poeta de la pareja de aparecidos es Pedro Salinas. } \\
\text { Su oficio es enseñar Lengua y Literatura españolas en la } \\
\text { Universidad literaria de Sevilla. }\end{array}$ & $\begin{array}{l}\text { Información personal } \\
\text { del autor }\end{array}$ \\
\hline $\begin{array}{l}\text { A sus treinta años, Presagios es el primer libro que publica. } \\
{[\ldots]} \\
\text { La moneda de cuño «Pedro Salinas», en su anverso, tiene este } \\
\text { emblema: poeta, y en su reverso este otro: erudito. Haríamos } \\
\text { bien en grabar en el canto: traductor. Buen traductor. Gracias } \\
\text { a él nos hemos podido despistar entre la tupida malla } \\
\text { psicológica de Marcel Proust. }\end{array}$ & $\begin{array}{l}\text { Comentario sobre la } \\
\text { obra del autor }\end{array}$ \\
\hline $\begin{array}{l}\text { Rastros hay en «Presagios» de la turbulencia espiritual de } \\
\text { Unamuno: aspiración constante a encontrarse en sí mismo, en } \\
\text { la vida y en el infinito. Escultor de su alma siempre, que } \\
\text { aprendió bien aprendido de Ángel Ganivet. }\end{array}$ & Influencias recibidas \\
\hline $\begin{array}{l}\text { Es un erudito y un poeta -escribe Antonio Marichalar-, pero a } \\
\text { su lirismo no le falta emoción sabrosa, prueba de que los } \\
\text { clásicos no dañan a todos. Al contrario, a Pedro Salinas sólo } \\
\text { le han influenciado benéficamente. Con ser su poesía } \\
\text { nacimiento de un pensar y sentir modernos, posee medula y } \\
\text { ornatos clásicos, de que carecen la mayoría de los otros poetas } \\
\text { creacionistas. [...] Sencillez, euforia, alegría, sentido claro de } \\
\text { las cosas, buen cultivo sin descanso: }\end{array}$ & $\begin{array}{l}\text { Comentarios sobre el } \\
\text { estilo del autor }\end{array}$ \\
\hline $\begin{array}{l}\text { «Columna mía; } \\
\text { de fuego hecha, } \\
\text { de la lumbre conocida }\end{array}$ & $\begin{array}{l}\text { Reproducción de } \\
\text { fragmentos de la obra } \\
\text { reseñada }\end{array}$ \\
\hline
\end{tabular}

21 Exordio general para las dos partes del artículo. 
por mí desde que he sentido

lumbre de vida»

Cuadro 2. Planteamiento general de la estructura de los artículos de prosa crítica de Francisco Valdés.

Este artículo se correspondería con el segundo tipo de crítica impresionista desarrollada por Valdés, ajustada al molde y formas del medio periodístico. Al igual que Darío, la estructura y elementos pueden fluctuar ligeramente. En relación al estilo, a diferencia de Darío, que opta por la alternancia de enunciados largos y breves, Valdés apuesta por una sintaxis sencilla donde predominan las oraciones simples, coordinadas y yuxtapuestas ("Sencillez, euforia, alegría, sentido claro de las cosas, buen cultivo sin descanso"). Al prescindir de la subordinación —o, al menos, al no emplearla de manera recurrente-, su prosa gana en agilidad:

Un pueblecito andaluz, límpido, lleno de luz y de paz. En la calle principal una casona vieja y fuerte que ostenta en la fachada un carcomido escudo heráldico, de bruñida piedra berroqueña. Por un amplio zaguán, fresco y húmedo, se llega a un patio -el clásico patio musulmán- grande, espacioso, cuadrilateral. Una fontana al centro con su perenne látigo de cristal que restalla en el pilón marmóreo su monorrítmica canturía. (Valdés 1914: 7)

En el terreno léxico, el estilo de Valdés se caracteriza, como apuntan Viola y Bernal (2013: 36), "tanto por la variedad y riqueza de su caudal, abierto a numerosos registros, como por su sorprendente precisión”, tal y como puede apreciarse en el fragmento anterior, tomado del artículo "Nuestros poetas. Antonio Machado” que publicó la revista Bética en noviembre de 1914.

\section{De Letras a Letras. Notas sobre la concepción de la obra valdesiana}

En 1911 vio la luz Letras, volumen en el que Darío muestra, "más que en otras colecciones de artículos, sus cuidados de escritor. Ante todo, su cuidado por el periodismo mismo" (Anderson-Imbert, 1967: 189). A diferencia de Los raros, donde rescataba a autores del XIX, algunos de ellos olvidados por la crítica, en Letras, y también en Opiniones (1906), Darío ofrece al lector comentarios sobre figuras representativas del arte moderno, "arte que merece la atención de un nuevo público” (Cardwell 1998: 57). Entre los propósitos del vate nicaragüense al concebir los artículos que conforman el volumen, y que fueron publicados originalmente en La Nación de Buenos Aires, estaba acercar a sus lectores a los artistas más "importantes e influyentes del momento" (Cardwell, 1998: 57). La literatura francófona tiene una presencia importante en el libro, como demuestran los cuadros dedicados a Eugénie de Guérin (1805-1848), Catulle Mendès (18411909), Maurice Maeterlinck (1862-1949) o León Daudet (1862-1947). Se fija en otros escritores europeos como el portugués Alberto Osorio de Castro (1868-1946), Filippo Marinetti (1876-1944) y Arthur Symons (1865-1945), al que confirma como uno de sus maestros. De la literatura española reivindica a Luis Bonafoux (1841-1909), Mariano de Cavia (1855-1920) y Antonio de Zayas (1875-1941). 
Dedica también sus comentarios a las letras brasileñas y dominicanas, que comienzan a abrirse hueco en la literatura moderna.

Por su parte, Francisco Valdés presenta un conjunto de "resonancias" literarias muy singular, "al ser estas porciones de biografía, momentos de vida consumidos en el ejercicio impenitente de leer, que implican ineluctablemente una visión literaria del mundo, transida del genial eco cervantino" (Bernal 1993: 31). El extremeño propone una serie de nombres clave, sus preferencias e impresiones lectoras. Así, en este libro, Valdés, como Darío en sus Letras, presenta comentarios y reseñas sobre la obra de autores del arte contemporáneo como Azorín, Gabriel Miró, Gerardo Diego, Juan Ramón Jiménez, Pío Baroja o Federico García Lorca. La nómina seguiría con Antonio Machado, Benjamín Jarnés, Francisco A. de Icaza, Villalón o Fortún. Como destaca José Luis Bernal (1993: 38), en el estudio introductorio de Letras, en este volumen

se reúnen solo 'Notas' literarias de autores contemporáneos o de libros contemporáneos, aunque su asunto se aleje en el tiempo (es el caso, por ejemplo, de 'La historia de Ajoxaní'), esto es, sugeridas a partir de un libro o libros de un escritor o de un motivo literario ligado a una resonancia libresca.

Tanto Darío como Valdés llevan esa crítica al terreno literario, es decir, literaturizan la obra que reseñan. En el caso de las Letras de Darío, puede apreciarse con mayor nitidez en "El pueblo del Polo", por ejemplo; en Valdés, en “Justa de poesía” o en “Arconada y Taramón”. No obstante, como planteábamos a propósito de la obra de Valdés, los límites entre géneros se desdibujan y dan paso a la fusión o a la presencia de elementos propios de la prosa impresionista en los capitulitos que articulan ambos volúmenes.

Francisco Valdés conocía bien el libro de Letras, como demuestran los comentarios que hace sobre la prosa de Darío y, en particular, de este volumen y de Opiniones, en el artículo de "Poesía y prosa" al que nos hemos referido anteriormente, publicado en el Correo de la Mañana el 24 de julio de 1925. La lectura de estos tomos despertó en él "deseos de escribir un centenar de cuartillas sobre la prosa del nicaraguo poeta: marcando su significación dentro del marco de la prosa española moderna que parte del romanticismo". Reconoce que Darío fue un innovador tanto en la poesía como en la prosa, "elevándola y dignificándola" (Valdés, 1925). Por ello, la elección de Letras como título a sus notas de lector, rúbrica bajo la cual aparecieron buena parte de los textos en diarios de la época, parece concebido como un homenaje a aquel.

\subsection{Estructura}

Las Letras de Darío y de Valdés presentan estructura similar. En ambos volúmenes se aprecia una técnica de yuxtaposición compositiva consistente en dividir los capítulos en varias partes numeradas en torno al mismo motivo. A propósito de las Letras de Valdés, Bernal (1993: 39) señala que la naturaleza de esta división puede ser cerrada o abierta. Habría, además, un tercer tipo de textos motivado por la naturaleza diferente del motivo que alienta la resonancia, y que 
agruparía las notas más líricas. El volumen de Darío lo componen 25 capítulos; el de Valdés, 14. En las Letras darianas, la estructura podría plantearse como sigue:

\begin{tabular}{|c|c|}
\hline Capítulos cerrados & 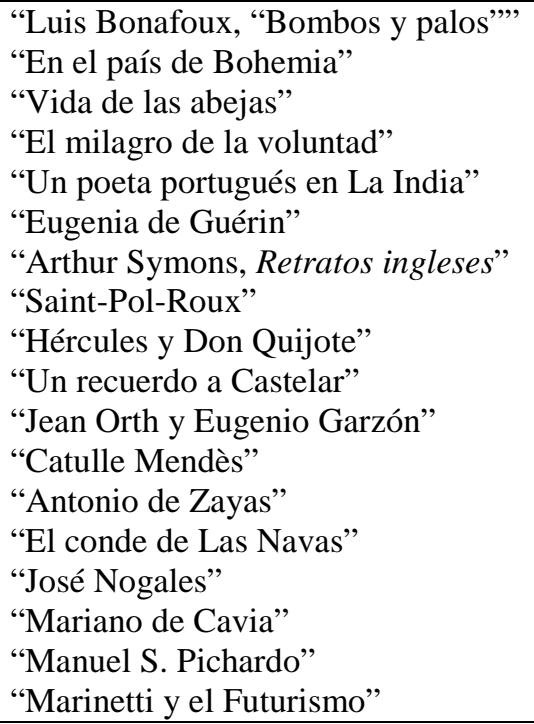 \\
\hline Capítulos abiertos & $\begin{array}{l}\text { "París y los escritores extranjeros" } \\
\text { "El Brasil intelectual" } \\
\text { "Letras dominicanas" }\end{array}$ \\
\hline Notas más líricas & $\begin{array}{l}\text { "La casa de las ideas" } \\
\text { "El pueblo del Polo" }\end{array}$ \\
\hline
\end{tabular}

Cuadro 3. Estructura de Letras (1911), de Rubén Darío

En las Letras de Valdés, por su parte, la estructura quedaría así:

\begin{tabular}{|c|c|}
\hline Capítulos cerrados & $\begin{array}{l}\text { “El dolorido sentir” } \\
\text { "Recordando a Miró” } \\
\text { "Erudito y poeta” } \\
\text { "La historia de Aljoxaní” } \\
\text { “Motivos sobre Juan Ramón” } \\
\text { “Tres fechas sobre Baroja” } \\
\text { "Paralelo soriano” }\end{array}$ \\
\hline Capítulos abiertos & $\begin{array}{l}\text { "Misivas" } \\
\text { "Poetas" }\end{array}$ \\
\hline Notas más líricas & $\begin{array}{l}\text { “Pueblos andaluces” } \\
\text { “¿Arconada o Taramón?” } \\
\text { “Justa de poesía” } \\
\text { “Un hidalgo” } \\
\text { "Un libro de viajes” }\end{array}$ \\
\hline
\end{tabular}

Cuadro 4. Estructura de Letras (Notas de un lector) (1933), de Francisco Valdés

Esta propuesta de estructura tiene su origen, por tanto, en la inclusión o no de motivos diferentes en un mismo artículo y de la naturaleza más lírica de otros. Podrían establecerse, no obstante, otras estructuras atendiendo al contenido (en 
escritores europeos, escritores americanos y notas líricas) o a la presentación formal de los textos (divididos o no en apartados, por ejemplo).

\subsection{Estilo}

A diferencia de los textos de Los raros, los apartados de las Letras de Darío son más breves. Como comenta el propio Valdés (1925) sobre la prosa del nicaragüense, "A veces el período se infla y ondula armonioso en cadencias sinfónicas. A veces se recorta con precisión”. En efecto, Darío mantiene un estilo marcado por la presencia de enunciados largos y breves, como indicamos en el apartado tercero, y como puede apreciarse en el siguiente fragmento:

Hoy la obra de un Lugones adquiere proporciones continentales; mas no se ignoran, en el Sur ni en el Centro de América, ni en las Antillas, los esfuerzos o la obra realizada de otros artistas de la palabra, de otros hombres de pensamiento, ni la constante virtud de entusiasmo que anima a los consagrados de la juventud. Hay mayor intercambio de ideas. Se comunican los propósitos y las aspiraciones. Se cambian los estímulos. (Darío 1911: 72)

En el libro de Valdés los capítulos son también breves, con una extensión similar a la de los textos de Darío. En una reseña sobre Letras, publicada en El Sol el 22 de marzo de 1933, y firmada por A. de O., se hace mención a la actualidad de los artículos agrupados en el volumen, hecho que proporciona al lector "una impresión amena y grata, tanto por la agilidad y altura con que están afrontadas, como por la elegancia de la prosa de Francisco Valdés, en esta, como en anteriores veces, triunfante con las claras ideas y los selectos sentimientos”. Hacia el final de la reseña, el crítico precisa que el extremeño "es un espíritu fuerte y español. Su estilo es por eso noble y austero”. Esa agilidad a la que se refiere A. de O. viene dada, en parte, por la elección de enunciados breves que se alejan de los periodos largos característicos de la prosa de Darío:

- Me quedo con Miró y con Juan Ramón Jiménez, entre los prosistas de ahora. En otro sentido distinto, Valle-Inclán, Azorín, Concha Espina, Menéndez Pidal.

Me sondearon los motivos de la selección y yo no supe qué contestarles. Era una hora indiscreta. Un lugar indeseable. Paseando por una calle muerta, al ocaso, quizá hubiera soñado las razones. (Valdés 1923: 70)

En definitiva, y a la luz de todo lo expuesto, podemos afirmar que la labor crítica de Rubén tuvo continuidad en escritores posteriores como Francisco Valdés, escritor periférico de la Edad de Plata pero figura crítica indiscutible de los principales diarios y revistas de las primeras décadas del siglo pasado. En sus obras, tanto Darío como Valdés redactan críticas y autocríticas que saben encontrar el lado vivo de la obra que comentan y recrear las sugestiones derivadas de esas lecturas. Consiguen destacar lo más poético y expresivo, pero también aquello que muchas veces pasa desapercibido por inusual. En el proceder crítico adoptado por ambos autores, lo humano se alía con lo estético; la crítica y la creación se funden 
en una. Lo que interesa realmente de estos críticos, más que su juicio, son su enfoque, sus planteamientos y sus implicaciones teóricas sobre literatura. La figura de Darío continuó vigente en la literatura española de las primeras décadas del siglo XX. Su método crítico se actualiza y toma forma en la prosa de Francisco Valdés, una prosa en la que demuestra un alto nivel literario tanto en las formas como en los autores y obras que glosa.

\section{Referencias bibliográficas}

Alonso, Dámaso. La poesía de San Juan de la Cruz. Madrid: Consejo Superior de Investigaciones Científicas, 1942.

Álvarez Gardeazábal, Gustavo. Manual de crítica literaria. Bogotá: Plaza y Janés, 2005.

Anderson-Imbert, Enrique. La originalidad de Rubén Darío. Buenos Aires: Centro Editor de América Latina, 1967.

Barthes, Roland. Le plaisir du text. Paris: Seuil, 1973.

Bernal, José Luis, “Introducción”, en Letras (Notas de un lector) de Francisco Valdés (). Mérida: Editora Regional de Extremadura, 1993, pp. 9-47.

Cardwell, Richard A., “Los Raros de Rubén Darío y los médicos chiflados”, en Cristóbal Cuevas García (ed.). Rubén Darío y el arte de la prosa. Ensayo, retratos y alegorías. Madrid: Publicaciones del Congreso de Literatura Española Contemporánea, 1998. pp. 55-77.

Caro Baroja, Julio. Semblanzas ideales. Madrid: Taurus, 1972.

Cernuda, Luis, 1994a [1933] "Unidad y diversidad”, en Derek Harris y Luis Maristany (eds.). Obras completas, vol. III, “Prosa II”. Madrid: Siruela, 1994a [1933], pp. 53-59.

— “Juan Ramón Jiménez”, en Derek Harris y Luis Maristany (eds.). Obras completas, vol. III, “Prosa II”. Madrid: Siruela, 1994b [1942], pp. 155-174.

Conejero, María Ángeles, “Rubén Darío, crítico literario”, Anales de literatura hispanoamericana, 14, 1985, pp. 223-236.

Darío, Rubén. España contemporánea. Paris: Hermanos Garnier, 1907.

-Letras. Paris: Garnier Hermanos, 1911.

-Opiniones. Madrid: Mundo Latino, 1917.

- Los raros. Obras completas, VI. Madrid: Mundo Latino, 1920.

-Cabezas: pensadores y artistas, políticos, novelas y novelistas. Madrid: Imprenta de Galo Sáez, 1929.

Gibson, Ian, "Federico García Lorca y Rubén Darío (con Pablo Neruda, atento, al lado)”, Dossier. Revista de la Facultad de Comunicación y Letras, Universidad Diego Portales, 23, 2014, pp. 55.62.

Guillén, Jorge, “Poesía de Pedro Salinas”, en Francisco Díaz de Castro (ed.). Obra en prosa. Barcelona: Tusquets, 1999 [1953], pp. 534-543.

López Prudencio, José, “La vida literaria en 1932”, ABC (01/01/1933), 1933a, p. 40.

—_La vida literaria en 1933”, ABC (31/12/1933), 1933b, p. 43.

Mainer, José-Carlos. La Edad de Plata (1902-1939). Ensayo de interpretación de un proceso cultural. Madrid: Cátedra, 1981.

Neruda, Pablo. Confieso que he vivido: memorias. Buenos Aires: Editorial Losada, 1974.

O., A. de., "Crítica. Francisco Valdés. "Letras” (Notas de un lector). Espasa-Calpe. Madrid, 1933”, El Sol (22/03/1933), 1933, p. 2.

Rovira, José Carlos, “La lección de Darío en la España de 1905: lo clásico como otro origen de la modernidad”, Cuadernos del CILHA, 10/11, 2009, pp. 128-137.

Rozas, Juan Manuel. La generación del 27 desde dentro. Madrid: Bella Bellatrix Istmo, 1987. 
Salinas, Pedro. La poesía de Rubén Darío. Barcelona: Seix Barral, 1975.

Urrutia Cárdenas, Hernán, “La Edad de Plata de la literatura española (1868-1936)”, Cauce. Revista de Filología y su didáctica, 22/23, 2000, pp. 581-595.

Utrera Torremocha, María Victoria, "La crítica literaria de Rubén Darío", en Cristóbal Cuevas García (ed.). Rubén Darío y el arte de la prosa. Ensayo, retratos y alegorías. Madrid: Publicaciones del Congreso de Literatura Española Contemporánea, 1998, pp. 79-102.

Valdés, Francisco, “Nuestros poetas. Antonio Machado”, Bética, 19 (05/11/1914), pp. 7-8.

- Cuatro estampas extremeñas con su marco. Madrid: Espasa-Calpe, 1924a.

— “Notas de un lector. Aparición de dos poetas”. Correo de la Mañana, 3353 (06/12/1924), 1924b, p. 1.

—_Poesía y prosa”, Correo de la Mañana, 3549 (24/07/1925), p. 1.

-8 estampas extremeñas con su marco. Madrid: Espasa-Calpe, 1932.

-Resonancias. Madrid: Espasa-Calpe, 1932.

-Letras. Notas de un lector. Madrid: Espasa-Calpe, 1933.

-Letras (Notas de un lector). Ed., intr. y notas de José Luis Bernal. Mérida: Editora Regional de Extremadura, 1993.

-8 estampas extremeñas con su marco. Edc., intr. y notas de M. Simón Viola y José Luis Bernal. Mérida: Editora Regional de Extremadura, 2013.

Viñas Piquer, David. Historia de la crítica literaria. Barcelona: Ariel, 2002.

Viola, M. Simón y José Luis Bernal Salgado (eds.), “Introducción”, en Manuel S. Viola y José Luis Bernal (edc., intr. y notas). 8 estampas extremeñas con su marco de Francisco Valdés. Mérida: Editora Regional de Extremadura, 2013, pp. 9-39. 